\title{
The cost of asthma medicines
}

\section{Helen K Reddel \\ Professor \\ Woolcock Institute of \\ Medical Research \\ University of Sydney}

\section{Kirsty Lembke}

Program design lead NPS MedicineWise

Sydney

Nicholas J Zwar

School of Medicine University of Wollongong New South Wales

\section{Keywords}

asthma, cost of drugs,

medication adherence

Aust Prescr 2018:41:34-6

https://doi.org/10.18773/ austprescr.2018.011

\section{SUMMARY}

Most adults and adolescents with asthma require a preventer inhaler. In Australia these patients are often prescribed a combination inhaler containing a corticosteroid and a long-acting beta $_{2}$ agonist.

These combination inhalers increase the cost of treatment for patients and for government and may not provide extra benefit. Many patients can control their asthma using an inhaled corticosteroid alone for prevention of symptoms and flare-ups.

Most of the benefits of inhaled corticosteroids are obtained at low doses. To achieve these benefits it is important to check that the patient is using their inhaler correctly and regularly.

Shared decision making includes discussing the options for treatment. Offering a more affordable preventer regimen could aid adherence and lead to improved outcomes.

\section{Introduction}

Australian guidelines recommend that most adults and adolescents with asthma should be taking a preventer inhaler. This is to minimise symptoms, prevent a decline in lung function, and to reduce the risk of exacerbations and asthma-related death. ${ }^{1}$ For the majority of patients, most of these benefits can be achieved with low-dose inhaled corticosteroids (e.g. beclometasone 200 micrograms/day, budesonide 400 micrograms/day, ciclesonide 160 micrograms/day or fluticasone propionate 200 micrograms/day). However, in Australia, most patients are prescribed inhaled corticosteroids in combination with long-acting beta $_{2}$ agonists, $^{2,3}$ often at moderate or high doses. ${ }^{2}$ This is common practice, despite these combination products not being subsidised by the Pharmaceutical Benefits Scheme (PBS) for the initial treatment of asthma.

Adherence is higher with combination inhalers than it is with inhaled corticosteroids alone. However, Australian data show that less than 20\% of patients are being dispensed enough of either of these types of preventer inhaler to be taking their treatment regularly. ${ }^{2}$

\section{Cost considerations}

Out-of-pocket cost is a major factor contributing to poor adherence to treatment, ${ }^{4}$ including in Australia ${ }^{5}$ where most medicines are subsidised by the PBS. Patients may not necessarily be comfortable telling a doctor their concerns about prescription costs, but pharmacists frequently see cost-related decisions being made at the point of purchase. This is particularly the case for asthma, since short-acting reliever inhalers, such as salbutamol, are cheaper than inhaled corticosteroids and have a rapid effect. However, reliance on reliever inhalers, especially without a preventer, increases the risks of severe asthma exacerbations. ${ }^{6}$

Many clinicians are not aware that the average cost for patients with most low-dose corticosteroid-only preventers is substantially lower than treatment with a combination inhaled corticosteroid and long-acting beta ${ }_{2}$ agonist. There are several options for prescribing low-dose preventers for adults that give the lowest average monthly out-of-pocket cost for the patient. Consider the dose, the frequency of administration and the number of actuations (single metered doses) in each inhaler (see Table). When averaged over a year, the cost of a lowdose inhaled corticosteroid can be strikingly low, as little as $15-30 \%$ of the out-of-pocket cost of any combination inhaler.

\section{Inhaled corticosteroids are very effective - low dose and affordable cost do not mean low benefit}

For most patients, $80-90 \%$ of the benefit of inhaled corticosteroids is obtained with low doses, if taken regularly and correctly. For example, in a large community study, the risk of dying of asthma was lower for patients who were dispensed four or more low-dose corticosteroid inhalers per year compared with those who received none. ${ }^{7}$ In a large randomised controlled trial, the risk of serious exacerbations (emergency department visits, hospitalisations, death) was also halved and symptoms were significantly reduced with regular use of budesonide 400 micrograms/day, even in patients with symptoms as infrequent as once a week or less. ${ }^{8}$ 


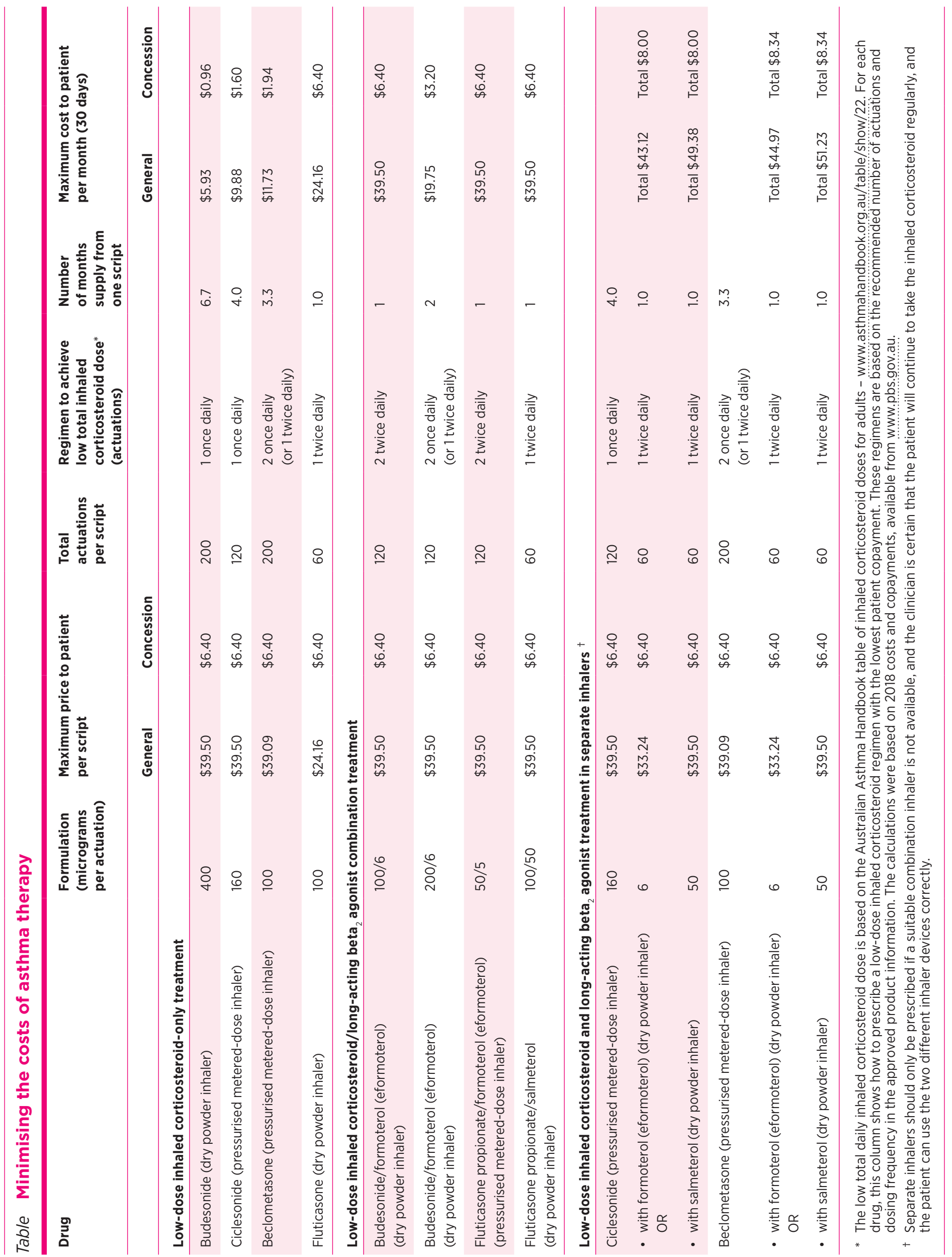




\section{Using a preventer inhaler correctly reduces treatment costs}

Patients can save costs by using their inhaler correctly. If their inhaler technique is incorrect, the drug is being wasted, as it does not reach the airways. This is the case for such a high proportion of patients (up to $80 \%$ ) that inhaler technique can be assumed to be incorrect until proven otherwise. Health professionals need to know the correct technique for the type of inhaler being prescribed, and watch the patient using it. Clear step-by-step videos are available online (www.nationalasthma.org.au/ health-professionals/how-to-videos, www.nps.org.au/ medical-info/consumer-info/inhaler-devices-forrespiratory-medicines).

\section{Book a review visit if treatment has been started or changed}

Patients usually start to feel the benefit from inhaled corticosteroids quite quickly, within 1-2 weeks, and they continue to improve for up to 18 months. If their asthma symptoms are still not controlled after 2-3 months, check adherence and inhaler technique before considering stepping up treatment to a combination of a low-dose inhaled corticosteroid and a long-acting beta ${ }_{2}$ agonist.

Combining a corticosteroid with a long-acting beta ${ }_{2}$ agonist reduces exacerbations on average by $20 \%$. These can be reduced further if low-dose budesonide/formoterol (eformoterol) is prescribed as 'maintenance and reliever therapy', that is as both the patient's regular maintenance inhaler (usually twice daily) and as their reliever inhaler (instead of salbutamol). However, contrary to expectations, adding a long-acting beta ${ }_{2}$ agonist has surprisingly little effect on the use of reliever inhalers. ${ }^{9}$ After asthma has been well-controlled for 2-3 months, treatment can be gradually stepped down to find the patient's minimum effective dose.

\section{Shared decision making improves asthma outcomes}

Shared decision making, either when treatment is first discussed or at a review visit, improves adherence and asthma outcomes..$^{10}$ As clinicians, we need to be aware of the contribution out-of-pocket costs have to patients' day-to-day adherence, and to know the cost implications of what we prescribe. For some patients, offering a more affordable option may make the difference between their choosing to take a regular preventer inhaler, and 'making do' with a reliever alone, with the attendant risk of worse outcomes. Given the difference in cost, many patients may be interested in trying an inhaled corticosteroid-only inhaler first, rather than a combination inhaler, if the likely benefit and its time course are explained. $<$

Helen Reddel has received honoraria for providing independent advice on advisory boards, steering committees and data safety monitoring boards for AstraZeneca, Boehringer Ingelheim, GlaxoSmithKline, Merck and Novartis. She has received honoraria for independent consulting for AstraZeneca and GlaxoSmithKline, and for providing independent medical education at symposia funded by AstraZeneca, Boehringer Ingelheim, GlaxoSmithKline, Mundipharma, Novartis and Teva. Professor Reddel has received independent research grants from AstraZeneca and GlaxoSmithKline.

Nicholas Zwar has received independent research funding from GlaxoSmithKline.

Acknowledgement: We thank Aine Heaney for her help with the manuscript.

\section{REFERENCES}

1. National Asthma Council Australia. Australian asthma handbook, version 1.3 Melbourne: National Asthma Council Australia; 2017. http://www.asthmahandbook.org.au [cited 2018 Mar 1]

2. Correll PK, Poulos LM, Ampon R, Reddel HK, Marks GB. Respiratory medication use in Australia 2003-2013: treatment of asthma and COPD. Canberra: Australian Institute of Health and Welfare; 2015. https://www.aihw.gov.au/getmedia/24aObaf9-1298-4178-8f42 66d71fc2df34/18879.pdf.aspx?inline=true [cited 2018 Mar 1]

3. Reddel HK, Beckert L, Moran A, Ingham T, Ampon RD, Peters MJ, et al. Is higher population-level use of ICS/LABA combination associated with better asthma outcomes? Cross-sectional surveys of nationally representative populations in New Zealand and Australia. Respirology 2017;22:1570-8. https://doi.org/10.1111/resp.13123

4. Patel MR, Kruger DJ, Cupal S, Zimmerman MA. Effect of financial stress and positive financial behaviors on cost-related nonadherence to health regimens among adults in a community-based setting. Prev Chronic Dis 2016;13:E46. https://doi.org/10.5888/pcd13.160005

5. Ampon RD, Reddel HK, Correll PK, Poulos LM, Marks GB. Cost is a major barrier to the use of inhaled corticosteroids for obstructive lung disease. Med J Aust 2009;191:319-23.
6. Stempel DA, Roberts CS, Stanford RH. Treatment patterns in the months prior to and after asthma-related emergency department visit. Chest 2004;126:75-80. https://doi.org/10.1378/chest.126.1.75

7. Suissa S, Ernst P, Benayoun S, Baltzan M, Cai B. Low-dose inhaled corticosteroids and the prevention of death from asthma. N Engl J Med 2000;343:332-6. https://doi.org/10.1056/NEJM200008033430504

8. Reddel HK, Busse WW, Pedersen S, Tan WC, Chen YZ, Jorup C, et al. Should recommendations about starting inhaled corticosteroid treatment for mild asthma be based on symptom frequency: a post-hoc efficacy analysis of the START study. Lancet 2017;389:157-66. https://doi.org/10.1016/S0140-6736(16)31399-X

9. Stempel DA, Raphiou IH, Kral KM, Yeakey AM, Emmett AH, Prazma CM, et al.; AUSTRI Investigators. Serious asthma events with fluticasone plus salmeterol versus fluticasone alone. N Engl J Med 2016;374:1822-30. https://doi.org/ 10.1056/NEJMoa1511049

10. Wilson SR, Strub P, Buist AS, Knowles SB, Lavori PW, Lapidus J, et al.; Better Outcomes of Asthma Treatment (BOAT) Study Group. Shared treatment decision making improves adherence and outcomes in poorly controlled asthma. Am J Respir Crit Care Med 2010;181:566-77. https://doi.org/10.1164/ rccm.200906-09070C

\section{FURTHER READING}

Usherwood T. Encouraging adherence to long-term medication. Aust Prescr

2017;40:147-50. https://doi.org/10.18773/austprescr.2017.050 